\title{
O apoio matricial na Atenção Primária em Saúde no município do Rio de Janeiro: uma percepção dos matriciadores com foco na Saúde Mental
}

\author{
I ${ }^{1}$ Luiz Fernando Chazan, ${ }^{2}$ Sandra Fortes, ${ }^{3}$ Kenneth R. de Camargo Jr., \\ ${ }^{4}$ Gabriele Carvalho de Freitas I
}

Resumo: Os cuidados adequados em saúde mental são considerados um desafio para a saúde pública. A integração desses cuidados com a Atenção Primária à Saúde (APS) é a principal estratégia segundo a OMS. Nesta direção, no Brasil, a criação do Núcleo de Apoio à Saúde da Família (NASF) foi um avanço, composto por uma equipe multidisciplinar que tem como principal ferramenta de trabalho o apoio matricial. O objetivo deste estudo foi analisar e explorar as percepçóes do trabalho dos matriciadores de saúde mental do município do Rio de Janeiro. Trata-se de uma pesquisa qualitativa, que usou grupo focal integrado à técnica do aquário, com 26 matriciadores de oito áreas programáticas. A análise de conteúdo se deu pela Análise Estruturada. Foi possível identificar questóes que versam sobre os dilemas da formaçáo de profissionais para APS e Saúde da Família, concepçôes diversas sobre apoio matricial, os impactos para profissionais e pacientes de questôes sobre violência e sobrecarga de trabalho, além do suporte da gestâo. Concluiu-se que, embora o NASF tenha apresentado avanços importantes na atenção à saúde, ainda é preciso haver uma integração maior dos profissionais e usuários para maior clareza do trabalho dos matriciadores, visando a um fortalecimento das açôes no âmbito do SUS.

Palavras-chave: apoio matricial; saúde mental; Atenção Primária à Saúde; grupo focal; cuidados colaborativos.

\author{
1 Faculdade de Ciências Médicas, \\ Universidade do Estado do Rio de \\ Janeiro. Rio de Janeiro-RJ, Brasil \\ (Ifchazan@hotmail.com). \\ ORCID: 0000-0001-8928-2240 \\ ${ }^{2}$ Faculdade de Ciências Médicas, \\ Universidade do Estado do Rio de \\ Janeiro. Rio de Janeiro-RJ, Brasil \\ (sandrafortes@gmail.com). \\ ORCID: 0000-0002-9918-1555 \\ ${ }^{3}$ Instituto de Medicina Social, \\ Universidade do Estado do Rio de \\ Janeiro. Rio de Janeiro-RJ, Brasil \\ (kenneth@uerj.br). \\ ORCID: 0000-0003-3606-5853 \\ ${ }^{4}$ Faculdade de Ciências Médicas, \\ Universidade do Estado do Rio de \\ Janeiro. Rio de Janeiro-RJ, Brasil \\ (gabi.cfreitas28@gmail.com). \\ ORCID: 0000-0002-2610-3003
}

Recebido em: 22/02/2018 Aprovado em: 27/02/2019 Revisado em: 22/05/2019 


\section{Introdução}

Os problemas de saúde mental (SM) são reconhecidos mundialmente como um desafio para a saúde pública (OMS, 2001), demandando a criação de políticas e açóes para ampliar o acesso de pessoas com sofrimento mental aos serviços de saúde, sendo a Atenção Primária à Saúde (APS) considerada a principal estratégia para este fim (OMS, 2008).

Os estudos da Organização Mundial da Saúde (OMS, 2010) e do Movimento pela Saúde Mental Global (MOVEMENT..., 2018) ratificam a importância da integração das açóes de SM na APS para melhorar a qualidade do cuidado às pessoas com problemas psicossociais e transtornos mentais com base nos direitos humanos e em evidências científicas (WENCESLAU; ORTEGA, 2015), sendo os cuidados colaborativos (collaborative care) os que apresentam melhor custo-efetividade (VAN ORDEN et al., 2009).

No Brasil, um dos avanços para qualificar e ampliar essa assistência foi a criação dos NASF em 2008, pela portaria ministerial 154/2008 (BRASIL, 2008), onde o Apoio Matricial (AM) se destaca como ferramenta fundamental para execução do trabalho (CHIAVERINI et al., 2011; BRASIL, 2014). O Apoio Matricial, termo cunhado por Gastão Wagner de Sousa Campos, tem como objetivo "ampliar as possibilidades de realizar-se clínica ampliada e integração dialógica entre distintas especialidades e profissóes", possibilitando dessa forma o suporte assistencial e técnico-pedagógico (CAMPOS; DOMITTI, 2007; CASTRO; CAMPOS, 2016). Representa o modelo proposto de cuidados colaborativos no SUS, e a Saúde Mental é onde está mais fortemente estabelecido.

Segundo o Histórico de Cobertura da SF em 2012, havia 1.412 equipes NASF tipo 1 para 32.498 equipes de Saúde da Família (eSF) implantadas no país; e em 2017, 2.825 equipes NASF tipo 1 para 42.119 eSF, sendo que cada equipe NASF tipo 1 deve apoiar até 9 eSF (BRASIL, 2018b). O rápido crescimento deste conjunto de cuidados primários de saúde depende de capacitação, apoio e supervisão para alcançar seus objetivos de integração e resolutividade (OMS, 2010).

A reforma da APS do município do Rio de Janeiro, que aconteceu no período de 2008 a 2016, ampliou a cobertura da Estratégia Saúde da Família (ESF) de 3,5 para 65\% (MINAYO; GUALHANO, 2017), aumentando o acesso da população aos serviços do SUS, em especial os indivíduos em sofrimento mental, o que evidencia 
a necessidade do reforço do apoio matricial (SORANZ et al., 2016). Entretanto, como nos mostram Fagundes Junior et al. (2016), existem barreiras à integração entre os profissionais da APS e da Saúde Mental. Dentre elas, destaca-se tanto a falta de treinamento dos médicos generalistas em relação aos transtornos mentais quanto a dificuldade/incapacidade dos profissionais de saúde mental em compreenderem a expressão do sofrimento mental no contexto da APS.

Ao se reconhecer, por um lado, o crescimento da cobertura da Saúde da Família e a criação dos mecanismos de integração SM-APS, como os NASF, torna-se fundamental compreender os entraves ao processo dialógico e integrador necessário para execução da proposta. Assim, o objetivo deste estudo foi analisar e explorar as percepçóes dos matriciadores de SM do município do Rio de Janeiro sobre sua prática.

\section{Metodologia}

Foi realizada pesquisa qualitativa utilizando-se GF (TRAD, 2009; DAWSON et al., 1993) integrado à técnica do aquário (Fishbowl technique) (MILLER; BENZ, 2008). Trata-se de um método adequado para que pessoas com experiências semelhantes discutam tópicos específicos da pesquisa permitindo, através da interação dos participantes, reflexóes, correçôes de percepçôes, trocas e questionamentos (YALOM; LESZCZ, 2006) que dificilmente surgiriam de outra forma.

O GF foi acordado com a Coordenadoria de Policlínicas e NASFs da Secretaria Municipal de Saúde (SMS) do Rio de Janeiro, que, em função das dificuldades para a liberação e deslocamento de pessoal das dez áreas programáticas (APs), solicitou que fosse realizado um único encontro. Como esta limitação poderia implicar o comparecimento de um número de matriciadores maior do que o adequado para a realização de GF, optou-se por associar a técnica do aquário. Esta consiste na formação de dois grupos dispostos em círculos, um interno que participa da discussão, e um externo em que os participantes observam e podem trocar de posiçôes com aquelas do grupo interno, a partir de um código pactuado antes do início da atividade.

Compareceram 26 pessoas de oito das dez áreas programáticas do município do Rio de Janeiro. Dois membros da equipe colaboraram na organização e observação do GF. Os participantes assinaram o termo de consentimento livre e esclarecido e preencheram um questionário com informaçôes sobre categoria profissional, tempo 
e formação em saúde mental, tempo e formação como apoiador matricial, formação em saúde da família, frequência da prática da consulta conjunta (escala Likert) e duas questôes abertas: 1) Cite um benefício do apoio matricial; e 2) Cite uma dificuldade de exercer o apoio matricial. A fala do grupo foi gravada e o registro, transcrito para melhor análise das falas.

O roteiro do GF abordava os seguintes temas: a concepção de NASF/AM dos profissionais da área, impacto do trabalho na equipe da ESF e pacientes, a aceitação e a integração do trabalho de AM pela Saúde da Família, estratégias utilizadas pela equipe para lidar com as dificuldades encontradas e a formação necessária para a prática de apoio matricial.

O método de análise de conteúdo escolhido foi Análise Estruturada (Framework analysis), criado e desenvolvido por Jane Ritchie e Liz Spencer na década de 80, no Reino Unido. Sua abordagem é indutiva, permitindo na codificação a inclusão de conceitos a priori e de conceitos emergentes de interesse da pesquisa. Este método permite a interpretação dos dados de forma estruturada, com classificação e organização em função de temas-chave e/ou conceitos. (SANTANA, 2014; GALE et al., 2013; SMITH; FIRTH, 2011).

A pesquisa foi aprovada pelo Comitê de Ética em Pesquisa da Prefeitura da Cidade do Rio de Janeiro, sob o número 4A/2015.

\section{Resultados}

\section{Descriçáo da amostra}

A amostra era composta por 26 participantes do sexo feminino, dentre as quais 17 psicólogas, três psiquiatras, três assistentes sociais, uma pediatra, uma enfermeira e uma terapeuta ocupacional. $\mathrm{O}$ tempo de formada variou de três a 38 anos (média: 17 anos) e o de trabalho com Apoio Matricial variou de seis meses a nove anos (média: três anos).

\section{Composição do grupo focal com a técnica do aquário}

O círculo interno foi composto por: sete psicólogas, dois psiquiatras, dois assistentes sociais e um pediatra, com representaçâo das oito APs e de pelo menos uma das categorias profissionais presentes. Duas psicólogas e um psiquiatra do círculo externo acenaram para entrar no grupo focal (GF), havendo troca de posição 
nos círculos, como previamente combinado. A duração do grupo foi de duas horas. A análise dos dados dentro dos temas-chave apresentou os seguintes resultados:

\section{1) Concepçáo de apoio matricial}

Dentro deste tema distinguiram-se dois conceitos orientadores das posturas profissionais nas práticas de matriciamento: horizontalidade e verticalidade, que influenciam as relaçôes entre as equipes do NASF e da ESF.

\section{Horizontalidade/diálogo}

A horizontalidade é um conceito estruturante da proposta de apoio matricial, pois esta se baseia em relaçóes dialógicas onde um saber não se sobrepõe hierarquicamente ao outro (SEVERO; DIMENSTEIN, 2011). No jogo do poder dos serviços, a verticalidade e a horizontalidade concorrem. A horizontalidade contribui para a distribuição do poder, buscando a coparticipação, reconhecendo a complementaridade dos saberes.

Destaca-se como a compreensão da questão da Saúde Mental enquanto campo e núcleo de saber (CUNHA; CAMPOS, 2011) pode trazer mais tranquilidade ao exercício da horizontalidade:

[...] questão do campo e do núcleo, que tem tantas coisas que são da saúde mental, mas que a equipe pode estar habilitada a estar cuidando [...] e há algumas questóes que serão do nosso núcleo da saúde mental e que a gente pode perceber também através da interconsulta [...] mas são coisas que não são da nossa prática totalmente, mas tem muitas que são incomuns que a gente pode estar ajudando e aprendendo com eles também, com as equipes.

Ainda nesta perspectiva de uma postura colaborativa, destacamos:

[...] tudo é negociaçáo. O tempo todo é negociação em cada unidade, com cada equipe para que esse trabalho possa fluir.

\section{Verticalidade/poder}

A verticalidade pode ser compreendida como o modo tradicional de lidar com o poder nos dispositivos de saúde, constituindo-se na hierarquia rígida e poder centralizado.

No grupo emergiram falas que demonstram a complexidade das relaçóes entre os distintos profissionais, persistindo a visão de que o especialista do NASF "supervisiona" o profissional da ESF: 
[...] nem chegar a ser uma consulta compartilhada, pode chegar só na discussão de caso, numa orientação.

Então às vezes eu costumo pensar que o trabalho do matriciamento é quase entender cada equipe ali como um caso. (Risos) E aí a gente vai trabalhando, intervindo na medida em que cada equipe funciona. E aí tipo apoio matricial, o que ele traz de diferente da formação, de como a gente fala de formação, de educação permanente, o que o apoio matricial traz de diferente, que não é a posiçáo de supervisão, mas ao mesmo tempo a gente também tem uma coisa que (inaudível) que é possível sim dar supervisão com relação à discussão de caso, eles esperam que você tenha um saber em relaçáo àquilo (grifo dos autores).

Essa postura pode ser superada à luz dos conceitos de núcleo e campo. Porém, a existência de sobreposição de limites entre os saberes profissionais (núcleos) pode acarretar conflitos identitários e desafios para a prática compartilhada dos saberes (campo) que é esperada no AM. O compartilhamento de um campo de competência que cria um cenário interdisciplinar necessita de segurança sobre o seu núcleo de saber, para um transitar em terreno multi e interdisciplinar, com uma postura colaborativa. Verifica-se que nem sempre isso acontece, subsistindo em muitos casos uma percepção da relação entre os dois participantes do processo como hierárquica, em termos de superioridade do saber do especialista sobre o profissional da equipe da ESF com função de orientá-lo.

\section{2) Formação para o trabalho na APS}

Dois aspectos se destacaram: a formação para desempenhar a função de matriciador em SM e a formação do médico da ESF.

\section{Formação dos matriciadores}

Dezoito participantes não tiveram formação em Saúde da Família, quatro mencionaram cursos curtos ou especialização latu senso, incluindo Gestão em Saúde da Família ou Residência em Saúde da Família, e três mencionaram formação em Saúde Coletiva ou Saúde Pública.

É possível constatar que os desafios começam na graduação, onde, em algumas categorias profissionais, o SUS não é contemplado no currículo:

O NASF também recebeu residentes multiprofissionais, nunca tiveram contato com essa população, nunca fizeram esse trabalho, e o problema é que, na maior parte das formaçôes, não tem nem o básico do que se trata a atenção primária. Na psicologia nem o SUS se aprende na faculdade, né? Então, realmente a graduação principalmente tem que mudar muito. 
As residências multiprofissionais, que são uma oportunidade de treinamento em serviço para a prática interprofissional, parecem deixar a desejar no âmbito do desenvolvimento de competências para o matriciamento:

[...] as próprias residências também ainda têm que mudar, algumas estão mudando, mas outras ainda estão muito embrionárias nessa discussão; e acho que é uma questão que a gente justamente, estando na ponta, a gente tem que estar preocupada em levantar e não sabe mesmo como agir, como fazer.

Quanto à pós-graduação, 13 participantes mencionaram alguma forma de aperfeiçoamento em SM por meio de cursos curtos (prevenção e tratamento em álcool e outras drogas), especialização (terapia de família, psiquiatria clínica, atendimento psicológico de crianças e adolescentes, psicodrama), residência em psiquiatria ou multiprofissional em SM ou mestrado em atenção psicossocial. Oito participantes mencionaram pós-graduação em áreas como Saúde Coletiva, Saúde Pública, Gestão em Saúde da Família, insuficientes como bagagem para o matriciamento:

[...] a grande dificuldade é as pessoas conhecerem o que é o matriciamento. Inclusive os matriciadores. [falam juntos]

A gente sabe na teoria o que tem o NASF, como ele devia trabalhar e depois na prática a gente vê que não consegue trabalhar.

Onze participantes referiram-se à formação em AM, mencionando o curso de aperfeiçoamento em SM na APS do Ministério da Saúde com a SMS RJ (Projeto Babel), o curso de AM na APS pela ENSP/Fiocruz e o curso de Formação de Apoiadores oferecido pela Universidade Federal Fluminense. Além disso, de treinamento em serviço durante a residência em Saúde da Família e na residência em Psiquiatria. Para a maioria, esta formação se dá principalmente na prática, onde o subsídio teórico para este trabalho está nos materiais do Ministério da Saúde, revelando uma subestimação da complexidade do trabalho na APS:

E no início realmente foi muito difícil. Difícil porque ninguém sabia exatamente o que estava fazendo.

A experiência foi me construindo como profissional, [...] eu acho que muitas vezes o próprio matriciador chega na estratégia Saúde da Família sem conhecer a estratégia de Saúde da Família, ele rapidamente lê o Caderno 39, entende que ele tem que atender junto[...] e repete os discursos das portarias, e aí a hora que ele entra mesmo para a consulta ele sabe fazer clínica tradicional, né? (BRASIL, 2014). 


\section{Formação dos médicos das equipes de Saúde da Família}

O padrão ouro para a formação do MFC é a Residência em Medicina de Família e Comunidade (RMFC) (BERGER et al., 2017), onde se estimula a compreensão dos fenômenos complexos dos processos de saúde-adoecimento e o desenvolvimento da abordagem centrada na pessoa. Este profissional trabalha no campo da integralidade biopsicossocial. No município do Rio de Janeiro, para viabilizar a reforma da APS, houve um investimento desde 2011 na ampliação de vagas dos programas de RMFC, utilizando as CFs como campos de prática, fato que não passa despercebido pelos matriciadores:

A maioria não tem formação, mas nos que têm a gente percebe uma diferença, que tem uma diferença [...] quando a gente fala em estratégia Saúde da Família uma diferença em concepção de saúde.

[...] quem tem formação em Saúde da Família tem uma disponibilidade maior para fazer as consultas conjuntas, de vir discutir os casos, eles não só querem o encaminhamento para o especialista dos NASF. Eles veem: "O que você acha, a gente marca uma consulta conjunta, não marca”. Eles querem estar juntos na consulta conjunta, então é uma formação bem diferente quando tem a residência em saúde da família.

No entanto, relatos como o que vemos abaixo acontecem quando o médico náo tem RMFC:

[...] médico que já disse: "Tudo bem, eu fazer consulta conjunta com outro médico, mas para que eu vou fazer consulta conjunta com psicólogo? Eu não sou psicólogo. Eu não quero aprender psicologia, eu não estudei psicologia, então para que eu vou gastar meu tempo, que é precioso?

Estudos sobre os indicadores de saúde revelam que os melhores resultados são atingidos pelas equipes de Saúde da Família com residência (ANDERSON; RODRIGUES, 2011). Entretanto, é expressivo o número de médicos na ESF que não possuem essa qualificação e não oferecem o cuidado longitudinal e integral adequado à população. Soma-se isso às condições adversas dos vínculos trabalhistas precários, da violência e pobreza da população sob seus cuidados, levando à alta rotatividade dos profissionais, oposto ao proposto na ESF.

A gente tem que falar também de OS, da rotatividade dos profissionais que não ficam, do médico que vem só para preencher um buraco na vida dele [...], enfim, toda essa outra dinâmica que também constitui a rede municipal de saúde que daí precariza o vínculo. 


\section{3) Integração e aceitação do NASF na Rede de Apoio Psicossocial (RAPS)}

A APS é fundamental na organizaçáo da RAPS (BRASIL, 2011), sendo esta uma das contribuiçóes do NASF, que começa no trabalho com as eSF, dependendo do apoio dos diferentes níveis da gestão e dos outros componentes da RAPS para ser resolutivo.

Quanto às dificuldades no AM, no questionário, 14 participantes destacaram as dificuldades das eSF, em entenderem o que é matriciamento, acarretando resistências para consultas conjuntas ou apoio. Outras respostas apontaram o excesso de demandas para eSF e indisponibilidade para o trabalho conjunto e a ausência de ambulatório de retaguarda. Foi citada também a divergência do entendimento do AM no próprio NASF.

\section{O suporte da gestão}

Um dos pontos mais abordados foi a relação população/eSF e a relação eSF/ NASF. As equipes vivenciam situações que são opostas ao proposto pela portaria 3.124/MS, que estabelece um máximo de nove equipes por NASF. Não há surpresa que o trabalho fique comprometido, considerando também as condiçóes de vulnerabilidade psicossocial da população:

[...] equipes NASF que estáo ganhando a terceira unidade para matriciar, indo para 15 equipes, 16 equipes; tem NASF com 17 equipes. Então, assim, cadê o apoio?

[...] a proposta em áreas vulneráveis é 2.500 habitantes. Então, por que numa área em que morrem dez, 12 pessoas por semana em tiroteio a gente tem cinco mil numa equipe?

O gestor das unidades é percebido como fundamental para o matriciamento. Gestor que não assume o AM inviabiliza o trabalho. É fundamental que ele esteja comprometido com os princípios da ESF e entenda o papel do NASF:

[...] na própria gestão que a gente vê as diferenças entre o gestor mais comprometido com o NASF, que integra e defende o NASF dentro da sua teoria até o outro que não defende o NASF.

[...] tem que passar pela equipe, essa conversa tem que ser, tem que ser, tem que ser. Aí, quando já tem gestor que banca isso e diz, como a minha diretora diz: "ACS já não marca agenda de NASF.”. Então, o ACS já não consegue jogar na nossa agenda, ele obrigatoriamente vai ter que jogar na da equipe, isso ganha ponto pra gente, mas porque a gestora bancou isso.

Sulti et al. (2015) demonstram que na gestão das unidades predomina uma lógica tradicional, baseada em açôes burocráticas, centralizadoras e hierárquicas. Porém, 
Magnago e Pierantoni (2015) relatam que dificuldades apontadas pelos gestores se relacionam ao entendimento do novo modelo de atenção da ESF. Essa dificuldade entre profissionais, gestores e usuários impacta negativamente nos processos de trabalho, pois não há compreensão de que esses trabalhadores possam contribuir de forma efetiva para a gestão, como seria esperado na concepção da ESF e na formação do MFC. Gestão compartilhada implica uma clareza conceitual e prática que nem sempre parece estar presente:

[...] horário de matriciar e a médica, coitada, estava louca, doida, e eu estava constrangida de ter que pedir meia hora para ela [...].

Estou vendo que ela está muito ruim, entáo vou ter que ver duas vezes na semana. Eu tenho uma equipe. É corresponsável? É. Só que aí o gerente está cobrando que os ACSs façam visita com balança, com fita para Bolsa Família.

Os consensos e as diretrizes são adaptados pelos matriciadores conforme as características pessoais e experiências prévias de cada um, revelando a fragilidade da coordenação, que contribui para a confusão acerca do matriciamento pelas equipes, do NASF e ESF.

[...] na minha equipe tem eu e outro psicólogo, e eu percebo que eu sou mais impositiva nesse sentido do que o outro psicólogo de falar: "Não, olha, é um paciente novo? Eu não conheço, a gente tem que fazer interconsulta, tem que ser junto"[...] Entáo, os profissionais já chegam para mim sabendo que vão marcar interconsulta, nenhum profissional mais, sei lá, mais de ano chega para mim querendo que eu atenda sozinha. Agora, para o meu colega, não. Pro meu colega, não: “Ah, você pode atender lá?” e zoom sai correndo (risos) porque sabe que ele aceita. Entáo isso é muito doido, na mesma unidade, o mesmo profissional que não me encaminha, encaminha para o meu colega, e aí você vai falar o que: "Ah, é a formação."

Não, é essa relação de trabalho mesmo que sabe com quem faz o quê, com quem faz outra coisa e tal.

\section{O papel da Rede de Atenção Psicossocial (RAPS)}

Observa-se importância do apoio matricial na ativação e no funcionamento da RAPS.

[...] no papel do apoiador matricial, identificando as demandas ali da instituiçáo, da equipe, da unidade é fazer essa articulação com outras instituiçôes, percebendo de repente que a equipe está um pouco sem perna para conversar com a escola, para conversar com o CAPs (Centros de Atençâo Psicossocial) e tal e então a gente poder fomentar isso, aquecer essa rede. 
Por outro lado, a sua insuficiência produz sobrecarga pelo esforço de tentar resolver, na própria unidade, situaçôes que deveriam ser complementadas no nível secundário.

[...] quando ele não se sente à vontade de participar do grupo e ele não tem recurso para o ambulatório, eu fico com o paciente acompanhando.

O ambulatório de SM foi excluído da RAPS (BRASIL, 2011) com a criação de um hiato nos dispositivos de assistência. Os pacientes graves com intenso sofrimento são acompanhados nos CAPs, os que possuem transtornos mentais comuns ou outros menos graves são acompanhados pelas eSF com o apoio matricial. Porém, os de gravidade intermediária, que se beneficiariam de psicoterapia, por exemplo, ficam em situação difícil ou são atendidos pelos matriciadores, o que deveria ser excepcional e não rotina (CHIAVERINI et al., 2011; RIO DE JANEIRO, 2016).

[...] pacientes que chegam, cada vez com mais acesso, com maior avanço da estratégia Saúde da Família, também a gente tem aumento da demanda, e como é que a gente faz com esses casos, principalmente as questôes que são de psicoterapia. Qual é a solução?

\section{Estratégias para o processo de trabalho em AM}

Foram abordadas as soluçóes encontradas para os problemas desta prática. Destacaram-se as dificuldades das psicólogas de fazer consultas conjuntas com alguns médicos, em especial os que não são MFC, caso em que existe até preferência por essa prática.

[...] Se fazer necessário, mostrar seu trabalho e dizer que você está ali, e às vezes procurar um outro momento, e num cafezinho puxar uma discussão de um caso e de repente a pessoa vai sentindo que ali tem uma parceria. Você não vai fazer consulta compartilhada com aquele médico porque ele não está a fim que você vá na sala dele, mas você vai fazer outras coisas, você vai atender separado e depois vai falar com ele sobre o que você fez, e isso você vai ganhando espaço, acho que é isso. Agora, com umas pessoas é possível; com outras, não.

Eu acho que eles ficam mais angustiados, entendendo como mais perda de tempo a discussão de caso. Eles veem muito mais sentido numa consulta conjunta do que na discussão de caso.

Efetivamente, a consulta conjunta permite uma resolubilidade maior e um aprofundamento da relação profissional eSF-matriciador. Permite aos participantes vivenciarem as diferentes escutas no compartilhamento da consulta e que o matriciador in loco observe os possíveis ruídos da comunicação do profissional da eSF e o paciente, oferecendo elementos para a atuação do matriciador como 
facilitador da comunicação entre profissional e pacientes. Por outro lado, a discussão em grupo permite um maior alcance de membros da eSF. São práticas complementares que fazem parte do rol de possibilidades do matriciador (CHIAVERINI et al., 2011; BRASIL, 2014).

Assim, de novo essa questáo da flexibilidade que a gente tem que ter de entender onde que a gente está, com quem a gente está, qual é o tempo que aquela pessoa tem disponível, se vai ter mais tempo com a enfermeira como revezar. Fazer consulta conjunta com o médico uma hora, com enfermeira em outra e por aí vai, [...]. Tem a tal da longitudinalidade, justamente para a gente poder ir vendo e revendo aquele paciente até entender qual o PTS que a gente vai conversar para aquele caso. Entáo assim, tem que conversar com a equipe. Se a gente parte de um modelinho fechadinho na nossa cabeça e póe um pacote assim na frente da equipe: Ó, é assim que a gente vai trabalhar! Está ferrado.

É importante refletir que o papel do matriciador envolve perceber a expectativa do profissional da eSF. Qual a formação que ele teve? Quer um trabalho colaborativo ou se ver livre de uma angústia fruto do sofrimento na interação com o paciente? Muitas vezes as insuficiências da formação são revistas e trabalhadas no AM, desde que o matriciador tenha a compreensão processual do trabalho

[...] nas minhas equipes, pelo menos, a maioria de demanda é pela manhã. Então eu privilegio o horário de consulta conjunta à tarde, que os profissionais estão mais tranquilos, tem menos gente na unidade, em turnos que o médico não está sozinho, o enfermeiro não está sozinho, porque tem turnos que uns saem para VD [visita domiciliar] outros têm que segurar a equipe inteira. Então, se estáo os dois na unidade, a minha consulta é com o enfermeiro; se houver demanda, o médico vai atender, o enfermeiro pode ficar tranquilo. Então eu acho que essa flexibilidade é fundamental, pelo menos na minha rotina é fundamental.

\section{d) Impacto do trabalho na equipe da ESF e pacientes}

Dos 26 participantes, seis enfatizaram como benefício do AM a corresponsabilização, troca de saberes ou o aprendizado mútuo, embora os demais também citem sua contribuição para o desenvolvimento de competências em SM das eSF. Os pacientes em geral emergiram como pessoas necessitando de cuidados. Apenas uma fala os cita como protagonistas corresponsáveis pelo seu processo de cuidado.

Percebeu-se que uma ética das relações (LAGANÁ, 2009) precisa ser desenvolvida. A construção do SUS implica reviravolta ética (LIMA et al., 2014), onde não basta que a configuração das equipes atenda ao manual, sendo necessário um compromisso 
com a cidadania, valorização das relaçóes interpessoais e reconhecimento do poder do outro em configuraçôes colaborativas.

[...] paciente também pode participar na gestão do autocuidado dele como a gente falou um pouco, eu acho esse projeto terapêutico singular, que às vezes não é sentar com a equipe e simplesmente rascunhar. Às vezes você não escreveu, mas você já fez um contrato ali com o paciente, uma pactuação que o médico estando junto aquilo pode dar continuidade. E uma das funçóes do matriciamento é isso, é ajudar a equipe a entender que o paciente ele precisa se responsabilizar também do autocuidado.

\section{4) Burnout (sobrecarga e violência)}

Há necessidade de suporte às equipes com objetividade e técnica. A atuação dos NASF em momentos de crise das equipes é esperada e necessária; porém, é difícil esta tarefa, já que o matriciador está inserido no mesmo contexto das equipes. $\mathrm{O}$ trabalho grupal operativo e, se possível em duplas, pode ser uma segurança para os matriciadores.

\section{Das equipes de Saúde da Família (eSF)}

As diferentes apresentaçôes da violência foram citadas como o problema mais prevalente no território. A sua relaçáo com o burnout das eSF e a alta rotatividade dos seus profissionais ficaram evidentes. São necessárias açôes de cuidado ao cuidador, e há disponibilidade de alguns matriciadores para tal; porém, estas não estão previstas na semana padrão das eSF:

Enfim, também tem a questão da vulnerabilidade do território, então isso traz impactos para a saúde mental do profissional, e eu acho que a gente fala muito pouco sobre isso, a gente fala muito pouco.

O nível de violência com unidades precisando ser fechadas e ameaças à integridade dos profissionais extrapola o âmbito do setor Saúde e exige ações políticas intersetoriais

[...] algumas tensões mais fortes, por exemplo, em relação à violência. Tem territórios que as pessoas estão pensando inclusive em rever a localização da unidade, porque tem unidade toda furada de balas, tem unidade que a população não consegue acessar por conta da divisão de facção.

Conviver com a violência aumenta a vulnerabilidade e as demandas por cuidados em SM da população gerando sobrecargas, no volume do trabalho e nas angústias das eSF e do NASF. 
[...] que nesse compartilhamento do sofrimento, a tendência é meio que todo mundo emburacar, né? Então, como estar nesse lugar de cuidar sem se descuidar e sem afundar junto com as pessoas [...]. Escuto desgraça o dia inteiro. Eu digo que nossos pacientes são pacientes cebolinhas, você tira uma camada aparece outra bomba, mais outra camada, outra bomba.

Além da violência, o contexto da vulnerabilidade socioeconômica, com altos níveis de miséria, impacta os profissionais, especialmente aqueles no início da formação.

[...] alguns dos residentes que estavam profundamente mobilizados com a situação como eles encontram alguns pacientes, com as casas, moradias, com as condiçóes de vida da população.

\section{Do NASF}

Neste cenário, as equipes NASF também são afetadas pela sobrecarga e necessitam de suporte, porém este acontece de maneira irregular.

Eu acho muito importante. Lá na nossa área uma vez por mês a gente tem essa reuniāo do NASF com todos os NASF da AP.

A gente consegue uma vez no ano fazer realmente um espaço especial, um evento com algum cuidado assim não só de questôes institucionais, as questôes mesmo assim das pessoas falarem e às vezes até a gente conseguir ter aula de dança, espaço lúdico, reforço dos vínculos [...].

\section{Discussão}

Ao final do grupo foi perguntado aos participantes se alguém se arrependia de trabalhar no AM e a resposta foi um "não", em uníssono, evidenciando o vínculo dos matriciadores com o seu trabalho, a despeito das dificuldades vivenciadas no cotidiano.

Como pontos fortes desta pesquisa, destacamos o interesse dos matriciadores em SM em participar do grupo focal, o que pode revelar a necessidade de espaços de reflexão sobre a própria prática e a sua representatividade, incluindo diferentes categorias profissionais em $80 \%$ das APs. E, como fragilidade, pode-se apontar o fato de ter sido realizado apenas um grupo focal e o fato de os participantes do círculo interior terem sido voluntários, o que pode ter enviesado a amostra, com os mais experientes em AM. 
O processo de trabalho proposto na concepção do AM, com base em relaçóes horizontalizadas, depende da formação adequada tanto das equipes NASF quanto das eSF. Foi possível constatar no grupo que as eSF sem formação específica na área tendem a não compartilhar o cuidado e a "encaminhar" ao NASF os pacientes com "doenças mentais", enquanto para as equipes NASF sem a formação adequada, o modelo vertical, onde há imposição de saberes e condutas, precisa ser superado.

É importante mencionar como avanço o fato de $42 \%$ dos participantes apresentarem formação específica para o AM, como o curso de Aperfeiçoamento em Saúde Mental na APS, conhecido como "Projeto Babel”. A importância da literatura neste tema, tal como o "Guia Prático de Matriciamento em Saúde Mental” e os Cadernos do DAB, também foi destacada.

Salienta-se a importância das formações de graduação destas categorias profissionais serem voltadas para o SUS. Iniciativas como o PET GraduaSUS, lançado em 2015 (BRASIL, 2015) - que visava a ampliar a integração e teve como objetivo qualificar os processos de integração ensino-serviço-comunidade no currículo das graduaçôes das áreas da Saúde - têm sido fundamentais. Essa ação proporcionou aos estudantes uma maior compreensão dos princípios e práticas da APS, alinhadas às Diretrizes Curriculares Nacionais (DCN). Entretanto, no que se refere à gestão, têm sido observados retrocessos importantes a partir da aprovação da nova Política Nacional de Atenção Básica - PNAB (BRASIL, 2017), que afeta diretamente a ESF, trazendo mudanças e restriçôes ao trabalho e financiamento das eSF e do NASF, com redução de equipes e de carga horária, que têm impacto negativo no seu funcionamento.

\section{Conclusão}

Dez anos após a criação dos NASF, ainda que sejam grandes os desafios para a implantação de novos modelos e garantia da efetividade de suas açôes, observaramse avanços nas práticas e na formação, tanto nas equipes de Saúde da Família quanto nas equipes dos NASF. Entretanto, em vista da aprovação da nova PNAB, as perspectivas atuais não são otimistas, dificultando que as intervençôes de cuidado à população mais carente sejam desenvolvidas e implementadas. Consolidar os avanços, produzir e ampliar novas ações de promoção à saúde exigem uma integração usuários e profissionais na defesa das conquistas do SUS como um todo. ${ }^{1}$ 


\section{Referências}

ANDERSON, M.I.P.; RODRIGUES, R.D. Formação de especialistas em Medicina de Família e Comunidade no Brasil: dilemas e perspectivas. Revista Brasileira de Medicina de Família e Comunidade, v. 6, n. 18, p. 19-20, 2011.

BERGER, C. B. et al. A formação na modalidade Residência Médica: contribuiçóes para a qualificação e provimento médico no Brasil. Revista Brasileira de Medicina de Família e Comunidade, v. 12, n. 39, p. 1-10, 2017.

BRASIL. Ministério da Educação. Diretrizes Curriculares - Cursos de Graduação Disponível em: <http://portal.mec.gov.br/observatorio-da-educacao/323-secretarias-112877938/orgaos-vinculados82187207/12991-diretrizes-curriculares-cursos-de-graduacao>. Acesso em: 26 ago.2018a.

. Ministério da Saúde. Portaria n.154, de 24 de janeiro de 2008. Cria os Núcleos de Apoio à Saúde da Família - NASF. Diário Oficial [da] República Federativa do Brasil. Brasília: Gabinete do Ministro, 2008. Seção 1, p.47-50.

. Ministério da Saúde. Portaria no 2.436, de 21 de setembro de 2017. Aprova a Politica Nacional de Atenção Básica estabelecendo a revisão de diretrizes para a organização da Atenção Básica, no âmbito do Sistema Único de Saúde. Brasília: Ministério da Saúde, 2017. Disponível em: $\quad<$ http://pesquisa.in.gov.br/imprensa/jsp/visualiza/index.jsp?jornal=1\&pagina=68\&da ta=22/09/2017> Acesso em: 15 maio 2018.

. Ministério da Saúde. Portaria no 3.088, de 23 de dezembro de 2011. Institui a Rede de Atenção Psicossocial para pessoas com sofrimento ou transtorno mental e com necessidades decorrentes do uso de crack, álcool e outras drogas, no âmbito do Sistema Único de Saúde. Diário Oficial da República Federativa do Brasil, Brasília-DF, no 247, Seção 1, p. 230, 2011.

. Ministério da Saúde. Secretaria de Atenção à Saúde. Departamento de Atenção Básica. Núcleo de Apoio à Saúde da Família. Cadernos de Atenção Básica n. 39 - Brasília: Ministério da Saúde, 2014. Disponível em: <http://bvsms.saude.gov.br/bvs/publicacoes/nucleo_apoio_ saude_familia_cab39.pdf> Acesso em: 20 abr 2018.

- Ministério da Saúde. Secretaria de Atenção à Saúde. Departamento de Atenção Básica. Histórico Cobertura SF. Disponível em <http://dab.saude.gov.br/portaldab/historico_ cobertura_sf.php> Acesso em: 21 abr. 2018b.

- Ministério da Saúde. Secretaria de Atenção à Saúde. Departamento de Atenção Básica. Edital PET-Saúde/GraduaSUS, 2015. Disponível em: <http://portalarquivos2.saude. gov.br/images/pdf/2015/setembro/29/Edital-PET-GraduaSUS.pdf> Acesso em: 24 abr 2018.

CAMPOS, G. W. S.; DOMITTI, A. C. Apoio Matricial e Equipe de Referência: uma metodologia para gestão do trabalho interdisciplinar em saúde. Cadernos de Saúde Pública, v. 23, n. 2, p. 399-407, 2007. 
CASTRO, C. P; CAMPOS, G. W. S. Apoio Matricial como articulador das relaçóes interprofissionais entre serviços especializados e atenção primária à saúde. Physis: Revista de Saúde Coletiva. Rio de Janeiro, v.26, p. 455-81, 2016.

CHIAVERINI, D. H. et al. (Orgs.). Guia prático de matriciamento em saúde mental. Brasília, DF: Ministério da Saúde, 2011.

CUNHA, G. T.; CAMPOS, G. W. S. Apoio Matricial e Atenção Primária em Saúde. Saúde e Sociedade, São Paulo, v. 20, n. 4, p. 961-70, 2011

DAWSON, S. et al. International Nutrition Foundation for Developing Countries. A manual for the use offocus groups. Methods for social research in disease. New York: UNDP/World Bank/ WHO Special Programme for Research and Training in Tropical Diseases, 1993.

FAGUNDES JUNIOR, H. M. et al. Reforma Psiquiátrica no Rio de Janeiro: situação atual e perspectivas futuras. Ciência \& Saúde Coletiva. Rio de Janeiro, v. 21, n. 5, p. 1449-1460, 2016. GALE, N. K. et al. Using the framework method for the analysis of qualitative data in multidisciplinary health research. BMC Medical Research Methodology. London, v. 13, n. 1, 2013.

LAGANÁ, M. T. C. A ética do cotidiano e a Estratégia Saúde da Família (ESF). Saúde Coletiva, v.6, n. 34, p. 230, 2009.

LIMA, C. A. et al. Relação profissional-usuário de saúde da família: perspectiva da bioética contratualista. Revista Bioética, Brasília, DF, v. 22, n. 1, p. 152-160, 2014.

MINAYO, M. C. S.; GUALHANO, L. Rio de Janeiro e Lisboa juntas no aprimoramento da Atenção Básica em Saúde. SciELO em Perspectiva | Press Releases, 2017. Disponível em: <https:// pressreleases.scielo.org/blog/2017/03/20/rio-de-janeiro-e-lisboa-juntas-no-aprimoramento-daatencao-basica-em-saude> Acesso em: 25 abr 2018

MILLER, R. L.; BENZ, J. J. Techniques for Encouraging Peer Collaboration: Online Threaded Discussion or Fishbowl Interaction. Journal of Instructional Psychology, v.35, n.1, p.8793 Mar 2008. Available from: <https://login.proxy.library.msstate.edu/login?url=http://search. ebscohost.com/login.aspx?direct=true $\& \mathrm{db}=$ pbh\&AN=31780834\&login. asp\&site=ehost-live> Acesso em: 21 abr 2018

MAGNANO, C.; PIERANTONI, C. R. Dificuldades e estratégias de enfrentamento referentes à gestáo do trabalho na Estratégia Saúde da família, na perspectiva dos gestores locais: a experiência dos municípios do Rio de Janeiro (RJ) e Duque de Caxias (RJ). Saúde em Debate, Rio de Janeiro, v. 39, n. 104, p. 9-17, jan./mar. 2015.

MOVEMENT FOR GLOBAL MENTAL HEALTH. Disponível em: <http://www. globalmentalhealth.org/>. Acesso em: 21 abr 2018. 
ORGANIZAÇÃO MUNDIAL DA SAÚDE. Manual de Intervençôes Programa de Ação Mundial em Saúde Mental, 2010. Disponível em:<http://www.who.int/mental_health/publications/IG_ portuguese.pdf> Acesso em: 21 abr 2018.

- Organização Mundial de Médicos de Família. Integração da saúde mental nos cuidados de saúde primários: uma perspectiva global. Lisboa: OMS, 2008. Disponível em: <http://www. who.int/eportuguese/publications/Integracao_saude_mental_cuidados_primarios.pdf> Acesso em: 22 abr 2018.

. Relatório sobre a saúde no mundo 2001: saúde mental: nova concepção, nova esperança. Geneva: WHO, 2001.

RIO DE JANEIRO. Secretaria Municipal de Saúde. Nota Técnica, 4 dez 2016 SMS-RIO/ SUBPAV/SAP/CPNASF Recomendaçóes sobre o atendimento, instrumentos e ferramentas do psicólogo no trabalho dos Núcleos de Apoio à Saúde da Família (NASF). Disponível em:< https://saudementalcap10.files.wordpress.com/2017/01/nota-tecnica-nc2ba4-psicologia.pdf> Acesso em: 23 abr. 2018.

SANTANA, C. L. A. A integração da Saúde Mental na Estratégia Saúde da Família. Interface (Botucatu), Botucatu, v. 18, n. 51, p. 797-798, dez. 2014.

SMITH, J.; FIRTH, J. Qualitative data analysis: application of the framework approach. Nurse Res, v.18, n. 182, p. 52-62, 2011. Disponível em:<http://eprints.hud.ac.uk/18884/> Acesso em: 04 mar. 2018.

SEVERO, A. K. S.; DIMENSTEIN, M. D. Processos de trabalho e gestão na Estratégia de Atenção Psicossocial. Psicologia e Sociedade, v. 23, n. 2, p. 340-349, 2011.

SORANZ, D. et al. Eixos e a Reforma dos Cuidados em Atenção Primária em Saúde (RCAPS) na cidade do Rio de Janeiro, Brasil. Ciência \& Saúde Coletiva, v. 21, p. 1327-38, 2016.

SULTI, A. D. C. et al. O discurso dos gestores da Estratégia Saúde da Família sobre a tomada de decisão na gestão em saúde: desafio para o SUS. Saúde debate. Rio de Janeiro, v. 39, n. 104, p. 172-182, mar 2015.

TRAD, L. A. B. Grupos focais: conceitos, procedimentos, e reflexóes baseadas em experiências com o uso da técnica em pesquisa de saúde. Physis: Revista de Saúde Coletiva. Rio de Janeiro, v. 19, n. 3, p. 777-796, 2009.

WENCESLAU, L. D; ORTEGA, F. Saúde mental na atenção primária e Saúde Mental Global: perspectivas internacionais e cenário brasileiro. Interface. Botucatu, v. 19, n. 55, p. 1121-1132, dez. 2015. 
VAN ORDEN, M. et al. Collaborative Mental Health Care Versus Care as Usual in a Primary Care Setting: A Randomized Controlled Trial. Psychiatric Services, v. 60, n. 1, p. 74-9, 2009. Disponível em: <http://psychiatryonline.org/doi/abs/10.1176/ps.2009.60.1.74> Acesso em: 21 abr. 2018.

YALOM, I. D.; LESZCZ, M. Psicoterapia de grupo: teoria e prática. Porto Alegre: Artmed, 2006. 528p.

\section{Nota}

${ }^{1}$ L. F. Chazan realizou a observação participante, a análise dos dados, redação e aprovação da versão final, respondendo por seu conteúdo. S. Fortes orientou a metodologia, foi responsável pela revisão teórica do artigo e pela aprovaçáo final, e responde por seu conteúdo. K. R de Camargo Jr. orientou a metodologia, foi responsável pela revisão teórica do artigo e pela aprovação final, e responde por seu conteúdo. G. C. de Freitas participou da redação, avaliação final e responde por seu conteúdo. 


\section{Abstract}

\section{The matrix support in primary health care in Rio de Janeiro municipality: the matrix workers' perception in Mental Health}

Appropriate Mental Health care is considered a public health challenge. Integrating this care with Primary Health Care (PHC) is the main strategy according to WHO. In this direction, the creation of the Support Center for Family Health in Brazil was an advance, made up of a multidisciplinary team that has as main work tool the Matrix Support. This study aimed to analyze and to explore the perceptions of the work of the Mental Health matrix workers of the city of Rio de Janeiro. It is a qualitative research that used the Focal Group along with the aquarium technique with matrix workers from eight programmatic areas. Content analysis took place through Structured Analysis. It was possible to identify questions related to the dilemmas of the training of professionals for PHC and Family Health, different conceptions about matrix support, impacts for professionals and patients on issues of violence and work overload, and management support. It was concluded that although the SCFH has presented important advances in health care, there is still a need for greater integration of professionals and users for greater clarity of the work of the matrix workers, aiming at strengthening SUS actions.

Keywords: matrix support; mental Health; Primary Health Care; focus group; collaborative care. 